\title{
Device to determine the level of peripheral blood circulation and saturation
}

\author{
Tetyana I. Kozlovska ${ }^{a}$, Sergii V. Sander ${ }^{b}$, Sergii M. Zlepko ${ }^{a}$, Valentina B. Vasilenko ${ }^{c}$, Volodymyr S. \\ Pavlov $^{\mathrm{a}}$, Victoria P. Dumenko ${ }^{\mathrm{d}}$, Andrii Yu. Klapouschak ${ }^{\mathrm{a}}$, Marcin Maciejewski ${ }^{\mathrm{e}}$, Róża Dzierżak ${ }^{\mathrm{e}}$, \\ Wojciech Surtel ${ }^{\mathrm{e}}$ \\ ${ }^{a}$ Vinnytsia National Medical University, Department of General Surgery, Pirogova 56, Vinnytsia, \\ 21018 Ukraine; ${ }^{b}$ Vinnytsia National Technical University, 95 Khmelnitske Sh., Vinnitsa 21021, \\ Ukraine; ${ }^{c}$ Universidade Nova de Lisboa, Faculdade de Ciências e Tecnologia, 2829-516 Caparica, \\ Portugal; ${ }^{\mathrm{d}}$ Vinnytsia State Pedagogical University, Ostrozhskogo 32, Vinnytsia, Ukraine; ${ }^{\mathrm{e}}$ Lublin \\ University of Technology, Institute of Electronics and Information Technology, Nadbystrzycka 38D, \\ 20-618 Lublin, Poland
}

\begin{abstract}
The paper evaluated the diagnostic value of laser photoplethysmography when examining patients with chronic lower limb ischemia. A statistical analysis of the research results was made, and diagrams of relationship between the degrees of ischemia and blood flow are presented. Development of the device to determine the level of peripheral blood circulation and saturation was presented. Also additional accessories in the form of optical fibers for different applications were suggested.
\end{abstract}

Keywords: device, saturation, blood, peripheral, circulation.

\section{INTRODUCTION}

Violation of peripheral blood circulation is a common pathology, which can indicate a particular disease. Depending on the stage, age, features and terms of obliteration and reactivity, circulatory disorders of certain body parts are formed in each patient. Early diagnosis of such disorders is an important task for modern medicine, that requires the development of new and improvement of existing diagnostic tools. Such early diagnosis increases the chances of full recovery in the patient. Also, early diagnose means lower treatment cost, as more critical conditions require more advanced procedures and tools. Development of portable and simple to operate medical devices is also important for home monitoring of patients in less life - threatening cases. Additionally, ease of use and a clear and simple user interface is necessary fot the device to be successfull. This field of study is crucial in today's world, as more and more people require medical ettention due to constantly growing life expectancy and multiple health risks in older patients ${ }^{1}$. This provides new challenges for the constantly growing field of telemedicine and forces development of new devices for home monitoring of patients with chronic diseases.

\section{Know methods and techniques}

Today there are many diagnostics methods, which are based on the use of laser and optoelectronic devices. Among them is photoplethysmographic method, which allows measuring the blood flow as it moves through veins, arteries and capillaries. In comparison to other methods for diagnosis biological object (BO), for example photoacoustic method, can improve the reliability of registration hemodynamic blood supply ${ }^{2,3}$. Also, biological impedance, or bioimpedance, can be utilized for a similar effect.

\section{METHOD}

The development of photoplethysmographic diagnostics devices, that based on the detection of reflected or passed through the biological tissue optical radiation is very important. But the intensity of the radiation that is recorded by photodetector depends on the absorption capacity of matter. Primarily, it depends on internal structure of molecules and atoms, the radiation wavelength, absorbing sample thickness, temperature and absorbing centers concentration.

Photonics Applications in Astronomy, Communications, Industry, and High-Energy Physics Experiments 2016,

edited by Ryszard S. Romaniuk, Proc. of SPIE Vol. 10031, 100312Z · () 2016 SPIE

CCC code: $0277-786 \mathrm{X} / 16 / \$ 18 \cdot$ doi: $10.1117 / 12.2249131$ 


\section{Dual - band photoplethysmography}

In the blue region of the visible spectrum is the absorption maximum, the green and yellow $(500-600 \mathrm{~nm})$ region has a less absorption and it's absorbed by the red blood cells. Shorter wavelengths are absorbed by melanin. In the ultraviolet and far-infrared regions the light is absorbed by water. The red and near-infrared ranges have the least light losses on absorption. Therefore, these optical ranges are used for development of optoelectronic sensors for diagnosing peripheral blood circulation (Fig. 1).

Blood has the highest absorption capacity of the surrounding tissues, so the intensity of light, recorded by the detector is increased with reducing of blood volume. The wavelength and the distance between the light source and photodetector determine the depth of light penetration. Light in the green spectrum is suitable for measurements of surface blood flow in the skin and very shallow tissues, as it is not able to travel deep into the body. The light in the green-yellow region $(500-600 \mathrm{~nm})$ has the greatest depth of modulation. Near infrared region is suitable for blood flow measurements in the deeper tissues and can be used in cases where more penetration is needed. A red band is used to determine blood oxygen saturation as it is connected to the color of hemoglobin. Therefore, a two - band approach had to be adapted to ensure greater sensitivity for both shallow and deep measurements, which in turn increases the device's flexibility.

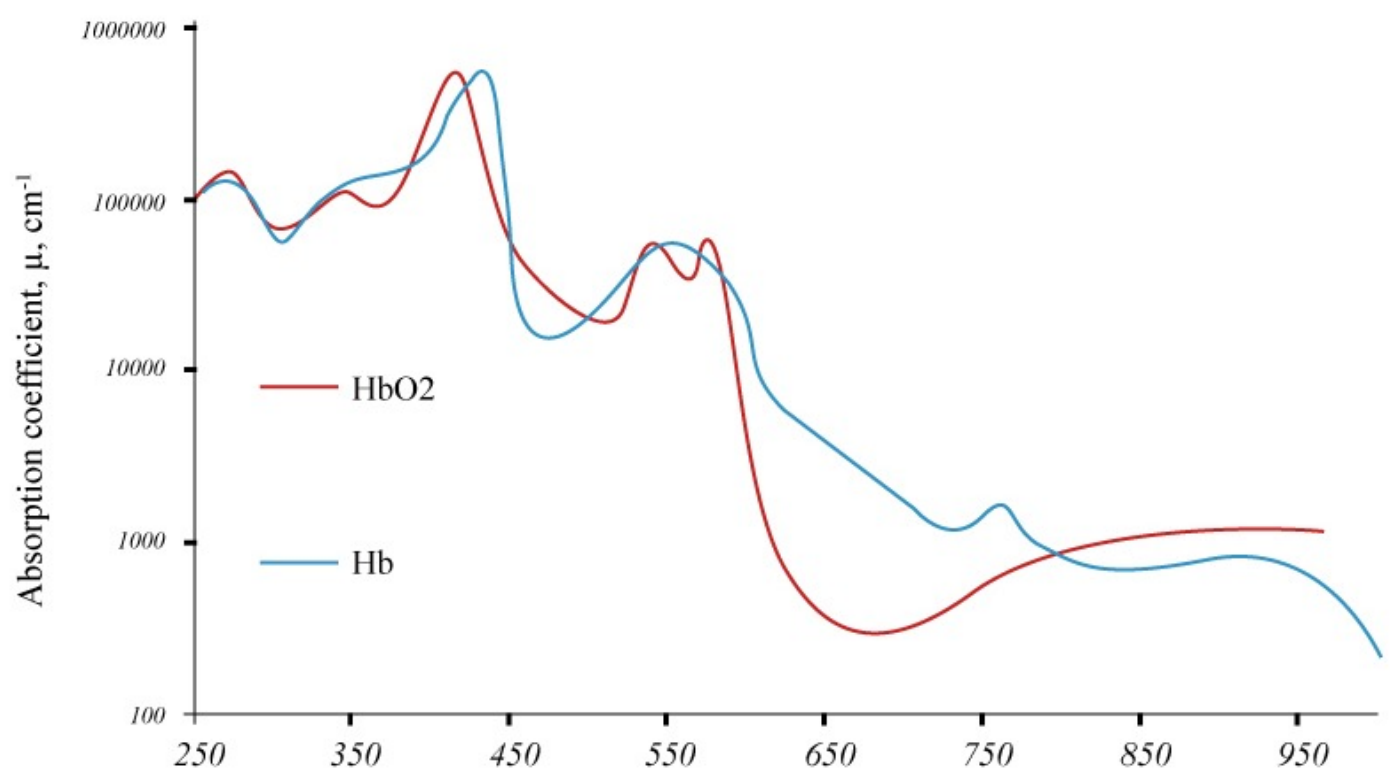

Wavelength, $\lambda, \mathrm{nm}$

Figure 1.Dependence the absorption coefficient on the wavelength

\section{PRACTICAL REALIZATION}

We have developed device to determine the level of the peripheral blood circulation, which determines the basic parameters of peripheral blood circulation and saturation level. The device consists of two sensors: infrared sensor 3, which contains the infrared radiation source 1 and photo detector 2, and the red sensor 6, which contains the red radiation source 4 and photo detector 5 (Fig. 2). The source and sensor combo ensures that proper wavelengths in both spectrums are emitted and then measured independently. The signal from the detector needed to be properly amplified and conditioned before sampling with the analog to digital converter, thus the outputs of the sensors connected to the inputs of the amplifiers 7 and 8 . The outputs of amplifiers are connected to the inputs of the converter included in the architecture of the micro controller used to perform calculations. These included solving appropriate equations for determining the parameters in question. Therefore, a device with proper processing power, memory and capabilities had to be utilized. 


\section{User interface}

To increase the mobility aspect of the device, a graphical liquid crystal display 12 is used. It displays the value of heart rate, blood saturation and blood circulation diagram (Fig. 3). This allows diagnosing the patients without a PC, it is important for examining postoperative patients. Also, providing such a screen allows for immediate assessment of measurement and easier error correction, for example in sensor placements. In addition, the device has a 14 slot for SDmemory card that is connected to the micro controller, it allows you to store data and transfer them later to a PC ${ }^{4,5}$. Such approach is necessary for further processing and research and long - term data acquisition.

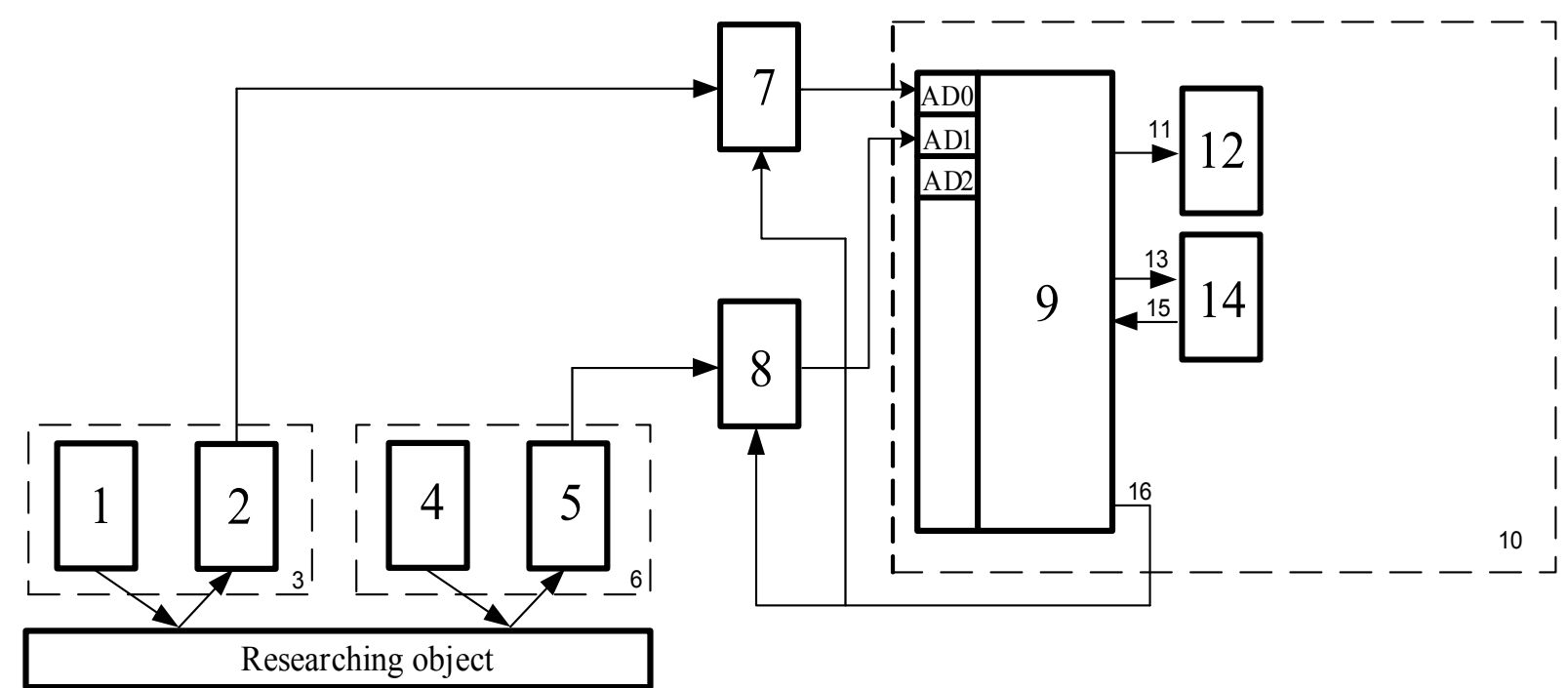

Figure 2. Block diagram of the developed device

To determine the blood saturation is used the composed equations for red $(\lambda 1)$ and infrared $(\lambda 2)$ ranges of radiation:

$$
\begin{gathered}
S=\frac{A_{\lambda_{1}}^{H b}-\alpha A_{\lambda_{2}}^{H b}}{\alpha\left(A_{\lambda_{2}}^{H b Q}-A_{\lambda_{2}}^{H b}\right)+A_{\lambda_{1}}^{H b}-A_{\lambda_{1}}^{H b Q}} \\
\quad \text { де } \alpha=\frac{\Delta V_{\lambda_{1}} V_{\min \lambda_{2}}}{\Delta V_{\lambda_{2}} V_{\min \lambda_{1}}}, \quad \Delta V_{\lambda}=V_{\max \lambda}-V_{\min \lambda}
\end{gathered}
$$

Where S - the saturation coefficient;

$A_{\lambda_{1}}^{H b}, A_{\lambda_{2}}^{H b}$ - extinction coefficients of the recombinant hemoglobin at the red and infrared wavelengths, respectively;

$\Delta V_{\lambda_{1}}, \Delta V_{\lambda_{2}}$ - double amplitudes of variable voltage in amplifiers outputs 7 and 8 , respectively;

$A_{\lambda_{1}}^{\mathrm{HbO}_{2}}, A_{\lambda_{2}}^{\mathrm{HbO}_{2}}$ - oxyhemoglobin extinction coefficients at the red and infrared wavelengths, respectively;

$A_{\lambda_{1}}^{H b}, A_{\lambda_{2}}^{H b}$ - extinction coefficients of the recombinant hemoglobin at the red and infrared wavelengths, respectively;

$V_{\max } \lambda \lambda, V_{\min } \lambda$ - maximum and minimum output voltage of the converter current-voltage at the wavelengths $\lambda_{1} \mathrm{i} \lambda_{2}$ (Fig. 4). 


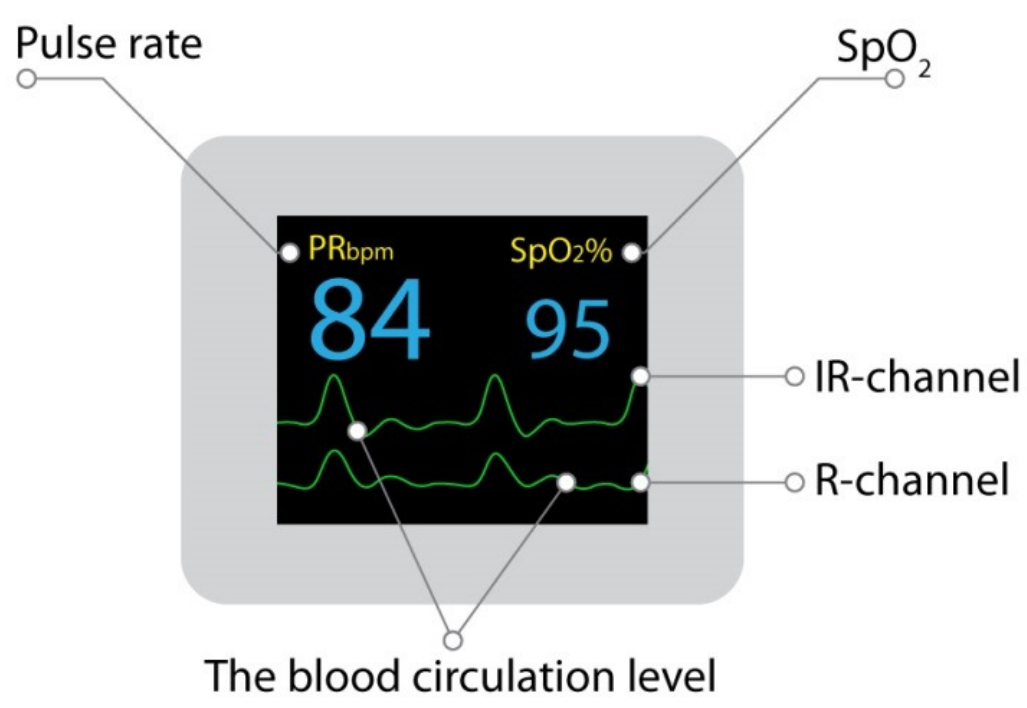

Figure 3. Example the displaying of information

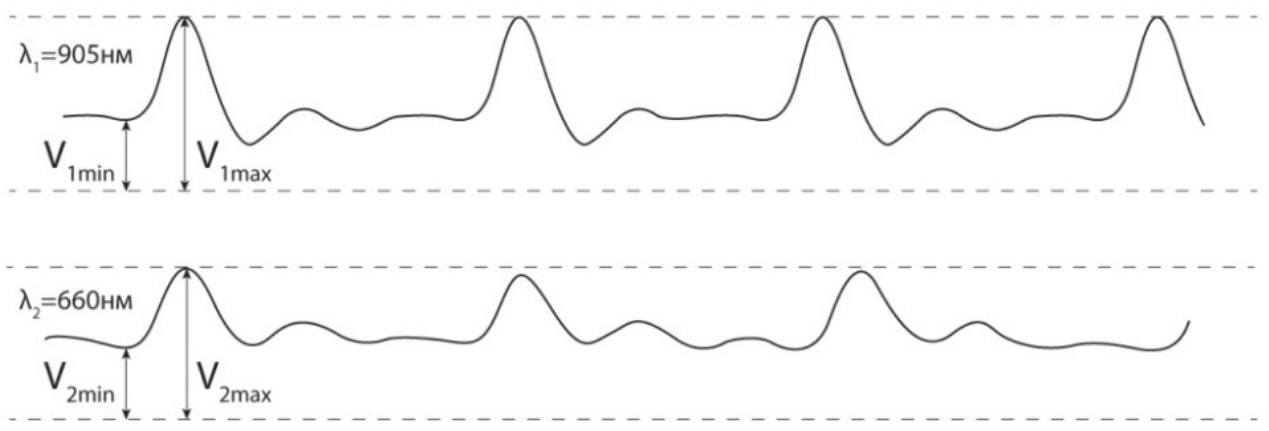

Figure 4. Maximum and minimum output voltage of the converter current-voltage at the wavelengths $\lambda_{1} \mathrm{i} \lambda_{2}$ determination

The developed device operates on the wavelength $905 \mathrm{~nm}$ for determination the basic parameters of peripheral circulatory and $660 \mathrm{~nm}$ for determination the blood saturation. The advantage of device is mobility and functionality ${ }^{6,7}$.

The developed device can also include additional optical systems and elements, which can be implemented in the form of fiber optic sensors. Modifications of fiber optic sensor were shown in Figure 5. It will allow rapid measurement of the circulatory disturbance in any part of the body ${ }^{8,9}$.

\section{Fiber optics integration}

The practical realization of this concept included three models for implementing optical fibers. The first model consists of one emitting optical fiber, which accepts the optical radiation from bio-object. The second model has been constructed on the base of the one emitting and the one accepting optical fibers. The last one consists of the one emitting and the group of accepting optical fibers ${ }^{10,11,12,13}$ (Fig. 5). 
a)

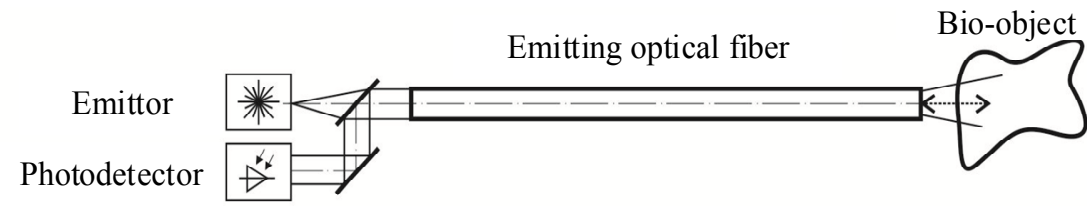

b)

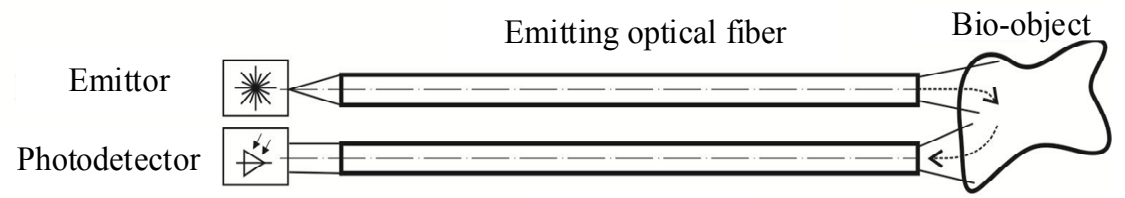

c)

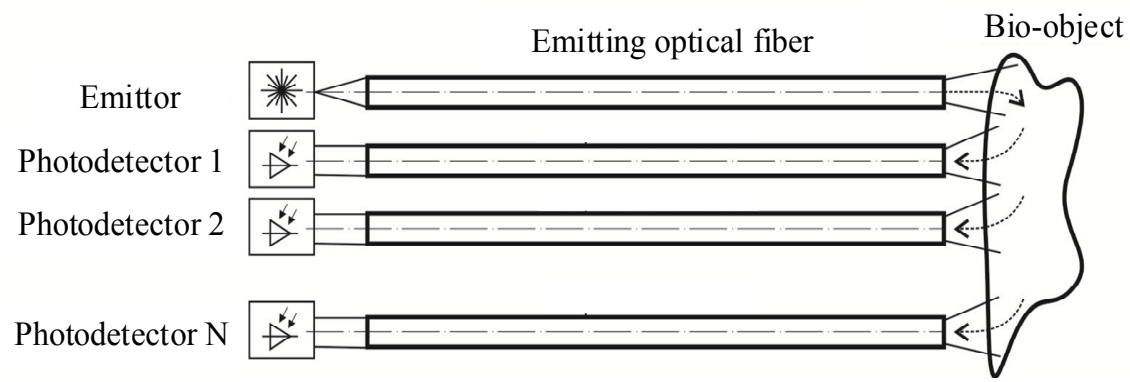

Figure 5. Options for construction of optical fiber

In the first two cases of this construction there are many advantages. Firstly, it permits us to use the sensor in samples of biological objects of small size, such as limbs of laboratory rats and mice or in remote places human mouth etc. Besides it provides a high concentration of the optical signal that permits us to research locally small areas of biological tissue. Such approach is also easier to handle in case of contact with biologically hazardous samples. The fiber can be made in a way that it can be sterilized in a dedicated solution or can even be single use, which is possible with low prices of optical fibers.

In another case we have more informative results, because we use the group of optical fibers and obtain biomedical data from different parts of biological objects surface. It is very important, when we are studying the spatial distribution of blood flow in tissue. Such approach can be used in hemorrhaging cases when trauma or other destructive factors were present and also determine the changes in blood flow on a greater area.

Dependence of efficacy of fiber optic sensors on the reflected optical radiation from biological objects is represented in Fig. 6.
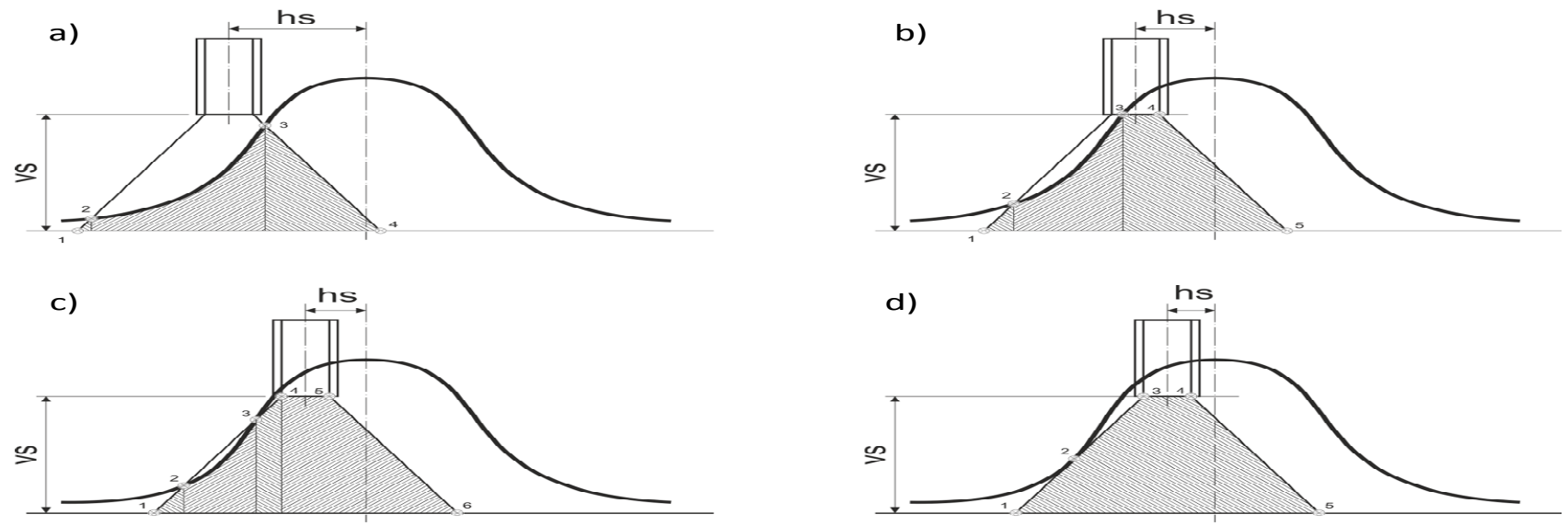

Figure 6. Dependence of location of fiber optic sensors on the reflected optical radiation from biological objects 


\section{CONCLUSION}

In the article we have developed the device to determine the level of peripheral blood circulation and saturation. Equations to determine the blood saturation were composed and a method for displaying of obtained information was proposed. Besides, the ways to use the fiber optic sensors in device were proposed for further development. The usage of fiber optics provides multiple benefits, like high precision in measuring a certain area and flexibility. The materials used to produce fibers can also be easily sterilized and stay biologically inactive, which is important in measuring in contact with living organisms.

\section{REFERENCES}

[1] Maciejewski, M., "Zastosowanie i ograniczenia technologii informacyjnych w diagnostyce medycznej," IAPGOS 5, (2015)

[2] Pavlov, S. V., Sander, S. V., Kozlovska, T. I., Kaminsky, A. S. and Wojcik W., "Laser photoplethysmography in integrated evaluation of collateral circulation of lower extremities," Proc. SPIE 8698, (2013).

[3] Pavlov, S. V. "Analysis of optoelectronic systems for pulse diagnostics," Modern problems of radio electronics telecommunications and instrumentation - Part 2: Fourth Intern. scientific-technical Conf. Vinnytsia, (2009)

[4] Pavlov, S. V., Kozlovska, T. I. and Dumenko, V. P. "Optical-electronic diagnostics of peripheral circulatory," Modern problems of radio electronics telecommunications and instrumentation Part 2: Fourth Intern. Scientifictechnical. Conf. Vinnytsia, (2009)

[5] Pavlov S. V., Kozlovska T. I. "Ukraine Patent 89377, IPC A61V 5.2. Optical-electronic device for peripheral circulation diagnostics, / ; patent owner. Vinnytsia National. Technical. University. № u201306212; appl. 05/20/2013; publ. 04.25.2014, Bul. № 8" (2014)

[6] Zlepko S. M, Sander S. V., Pavlov V. S. and Kozlovska T., "Ukraine Patent 98939, IPC A61V 5.2. Optical noninvasive device for determining the level of saturation of peripheral blood supply and blood, / I.; patent owner. Vinnytsia National. Technical. University. № u2014 13,182; appl. 12/08/2014; publ. 05.12.2015, Bul. № 9 "(2015).

[7] Zabolotna, N. I., Wojcik, W., Pavlov, S. V., Ushenko, O. G. and Suleimenov B. "Diagnostics of pathologically changed birefringent networks by means of phase Mueller matrix tomography," Proc. SPIE 8698, (2013)

[8] Rovira, R., Bayas, M. M., Pavlov, S. V., Kisała, P. and Yussupova, G., "Application of a modified evolutionary algorithm for the optimization of data acquisition to improve the accuracy of a video-polarimetric system." Proc. SPIE 9816, (2015)

[9] Zabolotna, N. I., Pavlov, S. V., Ushenko, A. G., Sobko, O. V. and Savich, V. O., "Multivariate system of polarization tomography of biological crystals birefringence networks.," Proc. SPIE 9166, (2014)

[10] Chepurna, O., Shton, I., Kholin, V., Voytsehovich, V., Popov, V., Pavlov, S., Gamaleia, N., Wójcik, W. and Zhassandykyzy, M. "Photodynamic therapy with laser scanning mode of tumor irradiation," Proc. SPIE 9816, (2015)

[11] Chepurna, O., Shton, I., Kholin, V., Voytsehovich, V., Popov, V., Pavlov, S., Gamaleia, N., Wójcik, W. and Zhassandykyzy, M. "Photodynamic therapy with laser scanning mode of tumor irradiation," Proc. SPIE 9816, (2015)

[12] Avrunin, O. G., Pavlov, S. V. and Kisała, P. "Classification of CT-brain slices based on local histograms.," Proc. SPIE 9816, (2015)

[13] Pavlov, S. V.; Vassilenko, V. B., Vovkotrub, D. V.; Poplavskaya, A. A. and Hotra, O., "Methods of processing biomedical image of retinal macular region of the eye.," Proc. SPIE 8698, (2013) 